\title{
Size and extranodal extension of metastatic lymph nodes in lung adenocarcinoma
}

\author{
Duk Hwan Moon $^{1,2 \#}$, Jin-Ho Choi ${ }^{1 \#}$, Hee Chul Yang ${ }^{1}$, Moon Soo Kim ${ }^{1}$, Jong Mog Lee ${ }^{1}$, Geon-Kook Lee ${ }^{1}$, \\ Jae Hyun Jeon ${ }^{3}$ \\ ${ }^{1}$ Center for Lung Cancer, Research Institute and Hospital, National Cancer Center, Goyang, Gyeonggi, Republic of Korea; ${ }^{2}$ Department of \\ Thoracic Surgery, Gangnam Severance Hospital, Yonsei University College of Medicine, Seoul, Republic of Korea; ${ }^{3}$ Department of Thoracic and \\ Cardiovascular Surgery, Seoul National University Bundang Hospital, Seoul National University College of Medicine, Seoul, Republic of Korea \\ Contributions: (I) Conception and design: JH Jeon; (II) Administrative support: HC Yang, MS Kim, JM Lee, GK Lee, JH Jeon; (III) Provision of study \\ materials or patients: HC Yang, MS Kim, JM Lee, GK Lee; (IV) Collection and assembly of data: DH Moon, JH Choi, JH Jeon; (V) Data analysis \\ and interpretation: DH Moon, JH Choi, JH Jeon; (VI) Manuscript writing: All authors; (VII) Final approval of manuscript: All authors. \\ \#These authors contributed equally to this work. \\ Correspondence to: Jae Hyun Jeon, MD. Department of Thoracic and Cardiovascular Surgery, Seoul National University Bundang Hospital, 82, Gumi- \\ ro 173 Beon-gil, Bundang-gu, Seongnam-si, Gyeonggi-do 13620, Republic of Korea. Email: fine1114@hanmail.net.
}

Background: This study assessed the prognostic significance of metastatic lymph node size (MLNS) and extranodal extension (EN) in patients with node-positive lung adenocarcinoma (ADC).

Methods: Prognostic factors influencing survival were analyzed, including age, sex, extent of operation, Tand N-stage, size of tumor, postoperative chemotherapy, presence of EN, and MLNS (>7.0 vs. $\leq 7.0 \mathrm{~mm}$ ).

Results: Three hundred seventy-five patients met the inclusion criteria were enrolled (mean age: $59.8 \pm 10.5$ years). Increasing MLNS was significantly correlated with large tumor size $(\mathrm{P}=0.015)$, advanced $\mathrm{N}$ status $(\mathrm{P}<0.001)$, and presence of $\mathrm{EN}(\mathrm{P}<0.001)$. In multivariable analysis, large tumor size [hazard ratio $(\mathrm{HR})$ $1.135,95 \%$ confidence interval (CI): 1.050 to $1.228, \mathrm{P}<0.001$ ], adjuvant chemotherapy (HR $0.582,95 \% \mathrm{CI}$ : 0.430 to $0.787, \mathrm{P}<0.001$ ), EN (HR $1.454,95 \% \mathrm{CI}: 1.029$ to $2.055, \mathrm{P}=0.034$ ), and MLNS greater than $7 \mathrm{~mm}$ (HR 1.741, 95\% CI: 1.238 to $2.447, \mathrm{P}<0.001$ ) were significant prognostic factors for survival. Patients were classified into 3 groups: Group A, MLNS $\leq 7.0 \mathrm{~mm} / \mathrm{EN}(-)$; Group B, MLNS $\leq 7.0 \mathrm{~mm} / \mathrm{EN}(+)$ or MLNS $>7.0 \mathrm{~mm} / \mathrm{EN}(-)$; and Group C, MLNS $>7.0 \mathrm{~mm} / \mathrm{EN}(+)$. The 5 -year overall survival (OS) was $72.2 \%$, $59.0 \%$, and $38.5 \%$ in Groups A, B and C, respectively $(\mathrm{P}<0.001)$.

Conclusions: The MLNS and presence of EN could provide an important prognostic implication for patients with node-positive lung ADC.

Keywords: Lung adenocarcinoma; lymph node metastasis; follow-up; surgery

Submitted May 26, 2020. Accepted for publication Oct 10, 2020.

doi: $10.21037 /$ jtd-20-2039

View this article at: http://dx.doi.org/10.21037/jtd-20-2039

\section{Introduction}

The tumor-node-metastasis (TNM) staging of non-small cell lung cancer (NSCLC) is crucial to determine the optimal treatment and predict the patient outcome. Among the TNM stages, T staging is determined based on various factors, including size, location, invasion, and satellite nodules (1-3). Moreover, according to the current lung cancer staging system ( $8^{\text {th }}$ edition), T descriptor is divided and configured based on a 1-cm tumor size intervals (1).

However, $\mathrm{N}$ staging is relatively simpler, with just three stages: N1, N2, and N3. The TNM staging system $\left(8^{\text {th }}\right.$ edition) recommends a more heterogeneous classification system, i.e., single station N1 (N1a) and multistation N1 (N1b) involvement, and single station N2 involvement without N1 (N2a1), combined single station N2 and N1 


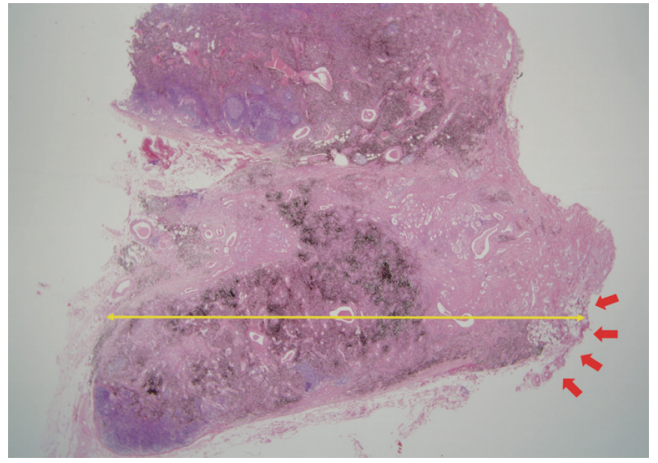

Figure 1 Histologic findings of lymph node metastasis in lung adenocarcinoma (hematoxylin and eosin; $\times 40$ ) Arrows indicate extranodal extension of lymph node metastasis. The metastatic cells in the lymph node invaded through the nodal capsule into the perinodal fatty tissue. Metastatic lymph node size was defined as the long-axis diameter of the largest metastatic focus of the metastatic lymph node (bidirectional arrow).

(N2a2) involvement, and multistation N2 involvement (N2b).; however, such a system has not been adopted in clinical practice to date (4), which is likely due to the lack of studies on lymph node (LN) metastasis. To date, the status of metastatic LNs has not been well defined for lung cancer, unlike other solid cancers, such as prostate, colorectal, thyroid, or breast cancers (5-11). According to previous studies, the prognosis may be poor in the case of extranodal extension (EN) existence or large metastatic $\mathrm{LN}$ in these solid cancers. However, there lacks studies evaluating whether the severity of LN metastasis has an impact on the prognosis of patients with NSCLC (5-10). Therefore, the question of whether the severity of $\mathrm{LN}$ metastasis impacts the prognosis of patients remains unanswered.

Herein, we evaluated the impacts of the status of $\mathrm{LN}$ metastasis in patients with lung adenocarcinoma (ADC). We focused on two factors that are well established in other solid cancers: the metastatic lymph node size (MLNS) and EN.

This article was prepared referencing the Strengthening the Reporting of Observational Studies in Epidemiology (STROBE) reporting checklist (available at http://dx.doi. org/10.21037/jtd-20-2039).

\section{Methods}

This study was conducted in accordance with the Declaration of Helsinki (as revised in 2013). As a retrospective study, patient consent was waived with the approval of our institutional review board (IRB number: NCC 2019-0064).

The patients' records of 1,787 subsets who underwent pulmonary resection for lung ADC from October 2002 to December 2014 were retrospectively reviewed and analyzed. We investigated the following parameters via medical record, telephone surveillance, and the Korean National Health Insurance Service (NHIS) database: demographic, clinical, treatment, and pathologic characteristics of patients and follow-up data for survival. The included patients were those who underwent complete anatomical resection and mediastinal LN dissection for pathologic stage N1 and $\mathrm{N} 2$ disease, and patients who received preoperative chemotherapy were excluded. Finally, 375 patients met the inclusion criteria were enrolled in the current analysis.

\section{Histopathologic reviews}

Patients included in this study underwent curative anatomic lung resection and systematic $\mathrm{LN}$ dissection (via lobectomy or greater, including bilobectomy and pneumonectomy). If LNs were positive, sections were cut and stained using hematoxylin and eosin $(\mathrm{H} \& \mathrm{E})$; these stains were examined by a thoracic oncology pathologist (L.G.K). In this study, the definition of EN was the tumor extending into the perinodal fibrous-adipose tissue through the capsule of LN (Figure 1). MLNS was defined as the long-axis diameter of the largest metastatic focus of the metastatic LN.

\section{Follow-up}

During the first two years of the postoperative followup period, surveillance was performed every 3 months; thereafter, surveillance was performed biannually and then annually after the fifth year. Recurrence was defined either by radiologic findings or histologic confirmation of a tumor. We defined overall survival (OS) as the period between the date of surgery and the date of death for any reason, and disease-free survival (DFS) as period between the date of surgery and the date of recurrence or death.

\section{Statistical analysis}

All statistical analyses were conducted using STATA 11.0 software (StataCorp, College Station, TX). For comparisons between the groups, descriptive statistics were performed; a chi-square test or Fisher's exact test was used for categorical variables, and Student's $t$-test was used for continuous 
Table 1 Clinicopathological characteristics of patients according to the size of metastatic lymph nodes and the presence of extranodal extension

\begin{tabular}{|c|c|c|c|c|c|c|}
\hline Variables & \multicolumn{3}{|c|}{ MLNS } & \multicolumn{3}{|c|}{ EN } \\
\hline Age, years & $58.9 \pm 11.1$ & $60.9 \pm 9.6$ & 0.075 & $60.1 \pm 10.6$ & $59.4 \pm 10.4$ & 0.521 \\
\hline Sex, male & $116(56.3 \%)$ & 86 (50.9\%) & 0.295 & $116(54.7 \%)$ & $86(52.8 \%)$ & 0.706 \\
\hline Tumor size, cm & $4.0 \pm 1.8$ & $3.5 \pm 1.6$ & 0.015 & $4.0 \pm 1.7$ & $3.5 \pm 1.6$ & 0.004 \\
\hline Pneumonectomy & $10(4.9 \%)$ & $7(4.1 \%)$ & 0.945 & $14(6.6 \%)$ & $3(1.8 \%)$ & 0.080 \\
\hline T stage & & & 0.597 & & & 0.120 \\
\hline T1 & $38(18.4 \%)$ & 38 (22.5\%) & & 38 (17.9\%) & 38 (23.3\%) & \\
\hline T2 & 142 (68.9\%) & 109 (64.5\%) & & 141 (66.5\%) & 110 (67.5\%) & \\
\hline N1 & $66(32.0 \%)$ & 94 (55.6\%) & & 85 (40.1\%) & 75 (46.0\%) & \\
\hline N2 & 140 (68.0\%) & $76(44.4 \%)$ & & 127 (50.9\%) & $88(54.0 \%)$ & \\
\hline EN (+) & $154(74.8 \%)$ & $58(34.3 \%)$ & $<0.001$ & & & \\
\hline MLNS > $7 \mathrm{~mm}$ & & & & 154 (72.6\%) & 52 (31.9\%) & $<0.001$ \\
\hline $\begin{array}{l}\text { Adjuvant } \\
\text { chemotherapy }\end{array}$ & 137 (66.5\%) & $120(71.0 \%)$ & 0.350 & 140 (66.0\%) & 117 (71.8\%) & 0.235 \\
\hline
\end{tabular}

MLNS, size of metastatic lymph nodes; VPI, visceral pleural invasion; EN, extranodal extension.

variables. The Kaplan-Meier method was used to estimate OS and DFS. Significant differences in prognostic factors were identified by log-rank tests. The effect of MLNS on survival was analyzed using logistic regression, and the maximal chi-square method was applied to examine a cutoff point of MLNS that divided patients into high- and low-risk groups $(12,13)$. We determined the cutoff point for MLNS at $7 \mathrm{~mm}$ with a corrected $\mathrm{P}$ value of $<0.001$. The influence of significant prognostic factors from the multivariable model was estimated using the Cox proportional hazards analysis. The variables with a $\mathrm{P}$ value of less than 0.20 were included in the final Cox proportional hazards model. A two-sided $\mathrm{P}$ value less than 0.05 was considered to indicate statistical significance. A professional statistician reviewed and verified the statistical analysis.

\section{Results}

Clinicopathologic characteristics of patients according to MLNS and EN

The median follow-up period for the 375 patients was
69.2 months, and the average number of dissected LNs was $28.8 \pm 9.7$. When patients were categorized into two groups according to the size of MLNS, the MLNS $\leq 7 \mathrm{~mm}$ group $(\mathrm{n}=169,45.1 \%)$ and the MLNS $>7 \mathrm{~mm}$ group $(\mathrm{n}=206$, $54.9 \%$ ), a greater MLNS was associated with presence of $\mathrm{EN}(\mathrm{P}<0.001)$, large tumor size $(3.5 \pm 1.6$ vs. $4.0 \pm 1.8 \mathrm{~cm}$; $\mathrm{P}=0.015)$, and advanced $\mathrm{N}$ status $(\mathrm{P}<0.001$, Table 1$)$. Among the study patients, 212 patients $(56.5 \%)$ were found to have EN. When these patients were classified into two groups stratified to the presence of EN, the EN-absence group $(\mathrm{n}=163)$ and the EN-presence group $(\mathrm{n}=212), \mathrm{EN}$ was associated with large tumor size $(3.5 \pm 1.6$ vs. $4.0 \pm 1.7 \mathrm{~cm}$; $\mathrm{P}=0.004)$, and large MLNS $(\mathrm{P}<0.001$, Table 1).

\section{Prognostic factors for survival}

The potential prognostic factors including age, sex, operation type, visceral pleural invasion, tumor size, $\mathrm{T}$ stage, N stage, MLNS, presence of EN, and adjuvant chemotherapy were evaluated in the study. Multivariable Cox proportional hazards model showed that tumor size 
Table 2 Prognostic factors for overall survival in patients with lymph node metastasis

\begin{tabular}{|c|c|c|c|}
\hline Variables & $\frac{\text { Univariate analysis (Log-rank test) }}{\mathrm{P} \text { value }}$ & \multicolumn{2}{|c|}{ Multivariable analysis (Cox hazards model) } \\
\hline Age, years & 0.176 & & \\
\hline Sex, male & 0.282 & & \\
\hline Pneumonectomy & 0.040 & & \\
\hline Tumor size, $\mathrm{cm}$ & $<0.001$ & $1.135(1.050-1.228)$ & 0.001 \\
\hline T stage (T1) & 0.076 & & \\
\hline T2 & & & \\
\hline T3 & & & \\
\hline EN (+) & $<0.001$ & $1.454(1.029-2.055)$ & 0.034 \\
\hline MLNS $>7 \mathrm{~mm}$ & $<0.001$ & $1.741(1.238-2.447)$ & 0.001 \\
\hline Adjuvant chemotherapy & $<0.001$ & $0.582(0.430-0.787)$ & $<0.001$ \\
\hline
\end{tabular}

$\mathrm{HR}$, hazard ratio; Cl, confidence interval; VPI, visceral pleural invasion; EN, extranodal extension; MLNS, size of metastatic lymph nodes.

[hazard ratio (HR) 1.135, 95\% confidence interval (CI): 1.050 to $1.228, \mathrm{P}=0.001$ ], adjuvant chemotherapy (HR $0.582,95 \%$ CI: 0.430 to $0.787, \mathrm{P}<0.001)$, presence of $\mathrm{EN}$ (HR 1.454, 95\% CI: 1.029 to $2.055, \mathrm{P}=0.034$ ), and MLNS greater than $7 \mathrm{~mm}$ (HR $1.741,95 \%$ CI: 1.238 to 2.447 , $\mathrm{P}=0.001)$ were independent poor prognostic factors for survival (Table 2). MLNS was also a significant risk factor for survival when it was considered as a continuous variable and the $7 \mathrm{~mm}$ cutoff was not employed (HR 1.045, 95\% CI: 1.022 to $1.069, \mathrm{P}<0.001)$.

\section{Survival curves according to MLNS and presence of EN}

Significant difference found between the survival curves for the MLNS $\leq 7 \mathrm{~mm}$ and MLNS $>7 \mathrm{~mm}$ groups $(\mathrm{P}<0.001$, Figure $2 A$ ). Moreover, there was also a significant difference between the OS curves for the EN-presence and ENabsence groups $(\mathrm{P}<0.001$, Figure $2 B)$. Patients were categorized into 3 subgroups: Group A, MLNS $\leq 7.0 \mathrm{~mm} /$ EN (-); Group B, MLNS $\leq 7.0 \mathrm{~mm} / \mathrm{EN} \mathrm{(+)} \mathrm{or} \mathrm{MLNS}$ $>7.0 \mathrm{~mm} / \mathrm{EN}(-)$; and Group C, MLNS $>7.0 \mathrm{~mm} / \mathrm{EN}$ $(+)$. The 5 -year OS was $72.2 \%, 59.0 \%$, and $38.5 \%$ in Groups A, B and C, respectively $(\mathrm{P}<0.001$, Figure $3 A)$. The 5 -year DFS was $43.5 \%, 31.3 \%$, and $18.4 \%$ in Groups A, $\mathrm{B}$ and $\mathrm{C}$, respectively $(\mathrm{P}<0.001$, Figure $3 B)$. There were
160 patients with $\mathrm{N} 1$ metastasis and 215 patients with $\mathrm{N} 2$ metastasis, and the subgroup analyses were conducted in these subsets. Among N1 patients $(\mathrm{n}=160)$, significant difference was found between the survival curves for the MLNS $\leq 7 \mathrm{~mm}$ group and MLNS $>7 \mathrm{~mm}$ group $(\mathrm{P}=0.023$, Figure $4 A$ ) and between the EN-presence and $\mathrm{EN}$-absence groups $(\mathrm{P}=0.004$, Figure $4 B)$. Among N2 patients $(\mathrm{n}=215)$, significant difference was identified between the survival curves for the MLNS $\leq 7 \mathrm{~mm}$ group and MLNS $>7 \mathrm{~mm}$ group $(\mathrm{P}<0.001$, Figure $4 C)$, as well as between the ENpresence and $\mathrm{EN}$-absence groups $(\mathrm{P}<0.001$, Figure $4 D)$.

\section{Discussion}

In this study, MLNS and EN were significantly correlated with large tumor size and advanced $\mathrm{N}$ status. Moreover, significant independent prognostic factors for survival were identified to be MLNS $>7 \mathrm{~mm}$ and presence of EN, along with the TNM staging system. When we stratified the analysis by $\mathrm{N} 1$ and $\mathrm{N} 2$ status, patients with MLNS $>7 \mathrm{~mm}$ and presence of EN had a worse survival rate than those with MLNS $\leq 7 \mathrm{~mm}$ and no presence of EN, regardless of nodal status.

At present, the $\mathrm{T}$ staging system involves a very careful classification based on tumor size, location, location, 
A

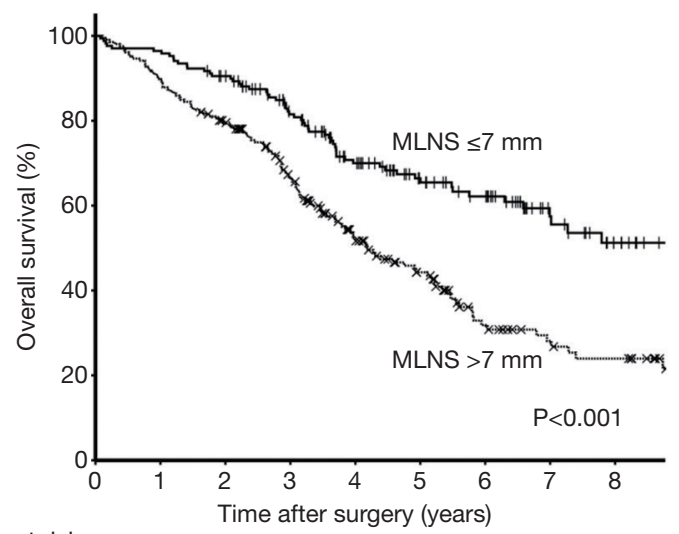

Number at risk

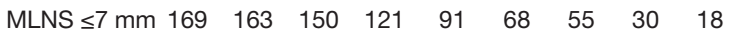

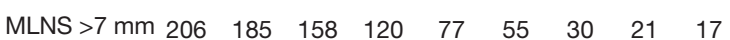

B

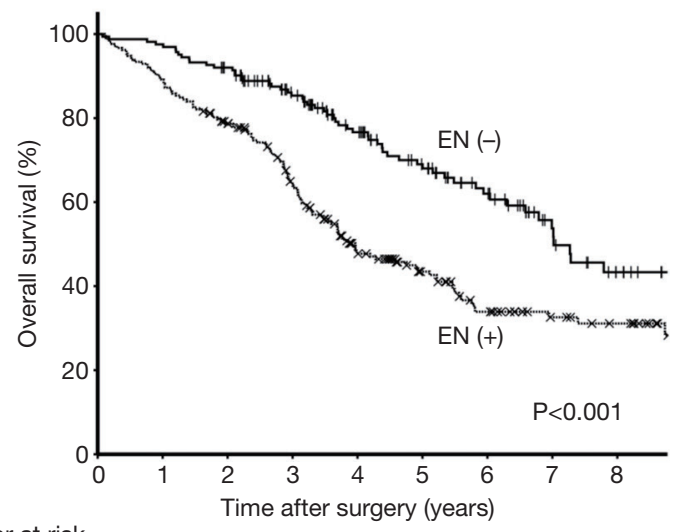

Number at risk

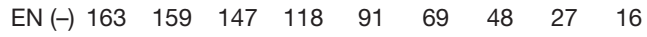

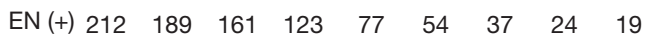

Figure 2 Overall survival curves stratified according to the MLNS (A) and presence of EN (B). MLNS, size of metastatic lymph nodes; EN, extranodal extension.

A

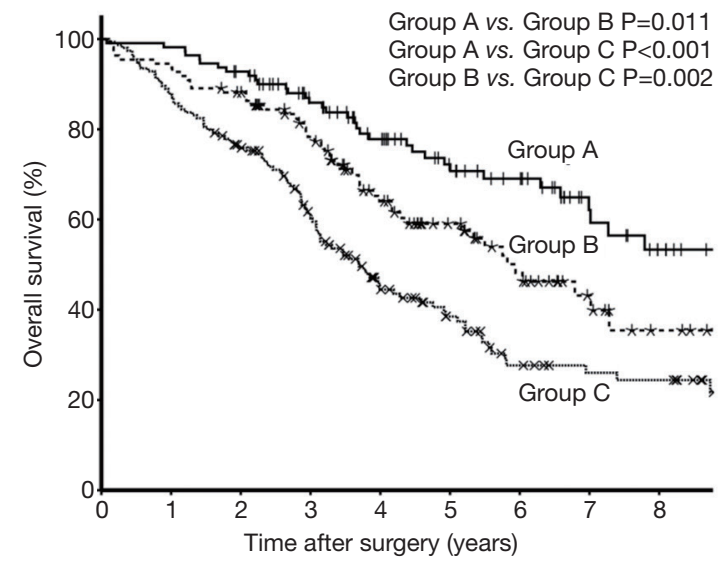

Number at risk

$\begin{array}{cccccccccc}\text { Group A } & 111 & 109 & 101 & 81 & 64 & 49 & 39 & 22 & 14 \\ \text { Group B } & 110 & 104 & 95 & 77 & 54 & 39 & 25 & 13 & 6 \\ \text { Group C } & 154 & 135 & 112 & 82 & 50 & 35 & 21 & 16 & 15\end{array}$

B

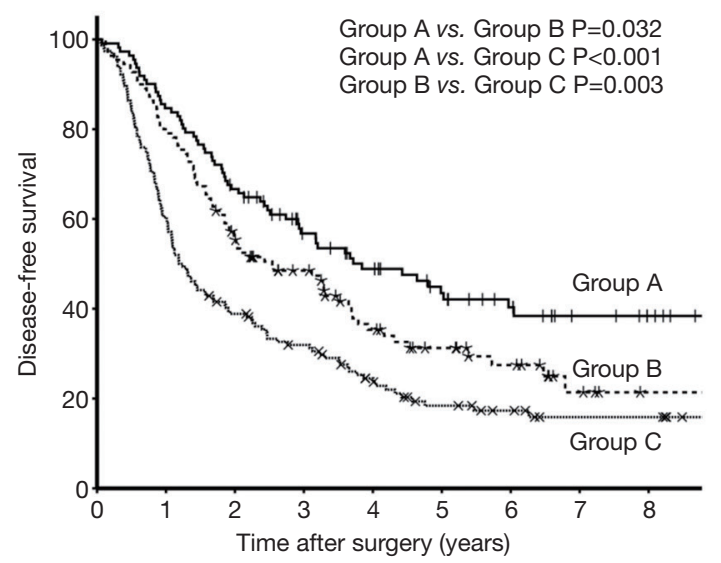

Number at risk

\begin{tabular}{|c|c|c|c|c|c|c|c|c|c|}
\hline Group A & 111 & 94 & 73 & 52 & 40 & 31 & 23 & 15 & 11 \\
\hline Group B & 110 & 88 & 59 & 45 & 28 & 20 & 14 & 6 & 2 \\
\hline Group C & 154 & 93 & 58 & 45 & 30 & 19 & 14 & 9 & 9 \\
\hline
\end{tabular}

Figure 3 Overall survival (A) and disease-free survival (B) curves stratified according to the MLNS and presence of EN [Group A, MLNS $\leq 7.0 \mathrm{~mm} / \mathrm{EN}(-)$; Group B, MLNS $\leq 7.0 \mathrm{~mm} / \mathrm{EN}(+)$ or MLNS $>7.0 \mathrm{~mm} / \mathrm{EN} \mathrm{(-);} \mathrm{and} \mathrm{Group} \mathrm{C,} \mathrm{MLNS}>7.0 \mathrm{~mm} / \mathrm{EN}(+)$ ]. MLNS, size of metastatic lymph nodes; EN, extranodal extension.

invasion, and satellite nodules $(3,14,15)$. However, despite a description of the heterogeneous situation, $\mathrm{N}$ staging is relatively simple; it is classified as N0, N1, N2, and N3 based on LN involvement (3). However, to date, there has been a number of studies evaluating the status of LN metastasis in other cancers, including gastric, colorectal, prostate, breast, and penile cancers, highlighting the importance of MLNS and EN (6-11,16,17).

In this study, MLNS was divided based on cutoff value of $7 \mathrm{~mm}$ ( $>7$ or $\leq 7 \mathrm{~mm}$ ). Based on the maximal chi-square test, MLNS $>7 \mathrm{~mm}$ was determined to be an important prognostic factor with statistical significance. Although the method of measuring the size of MLNs - specifically, whether the measurement should reflect the gross LN size or the size of metastatic foci-remains controversial in the literature, this conundrum may be irrelevant in cases of lung $\mathrm{ADC}$, since it is possible for anthracosis, tuberculosis, or other factors to cause LN enlargement (18-21). Hence, 
A
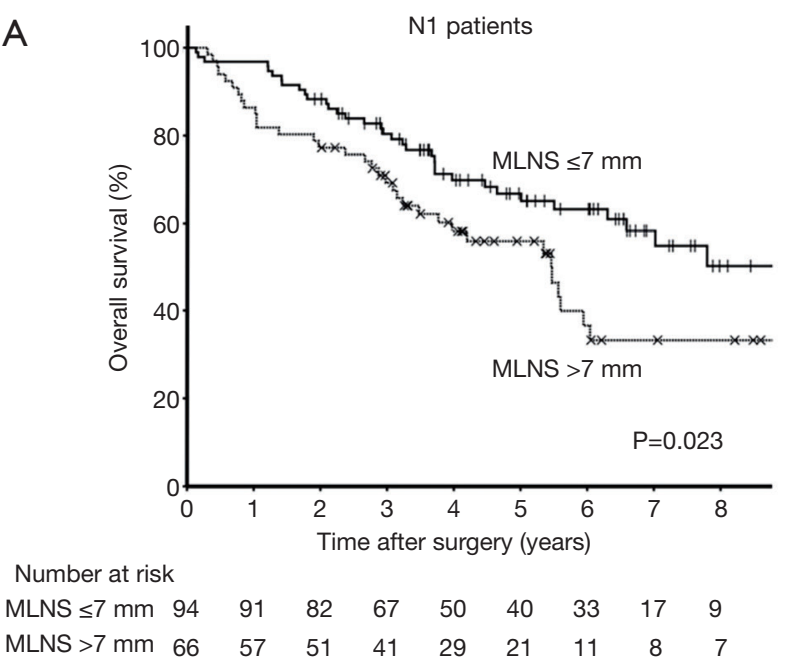

C

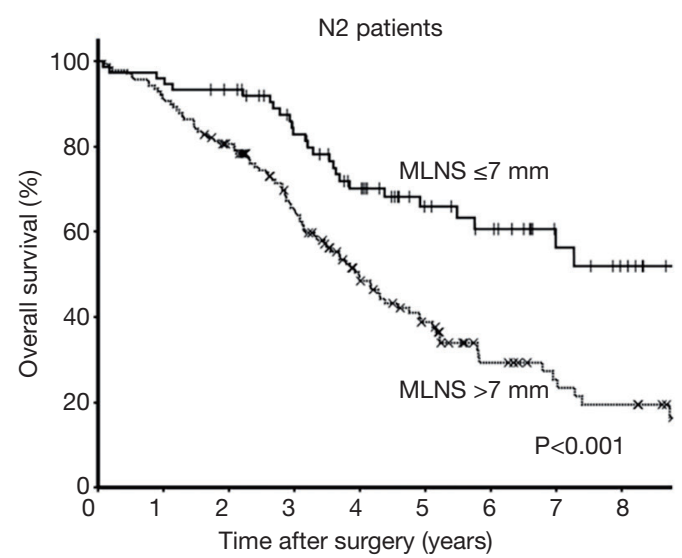

Number at risk

$\begin{array}{llllllllll}\text { MLNS } \leq 7 \mathrm{~mm} & 75 & 72 & 68 & 54 & 41 & 28 & 22 & 13 & 9\end{array}$

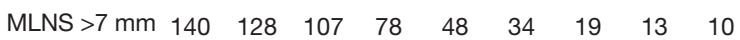

B

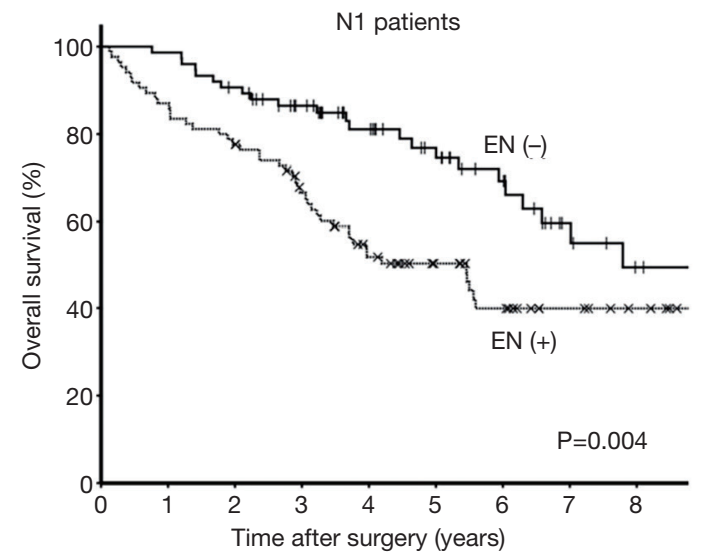

Number at risk

$\begin{array}{llllllllll}\text { EN (-) } & 75 & 74 & 67 & 56 & 43 & 34 & 25 & 13 & 9\end{array}$

$\begin{array}{llllllllll}\text { EN (+) } & 85 & 74 & 66 & 52 & 36 & 27 & 19 & 12 & 8\end{array}$

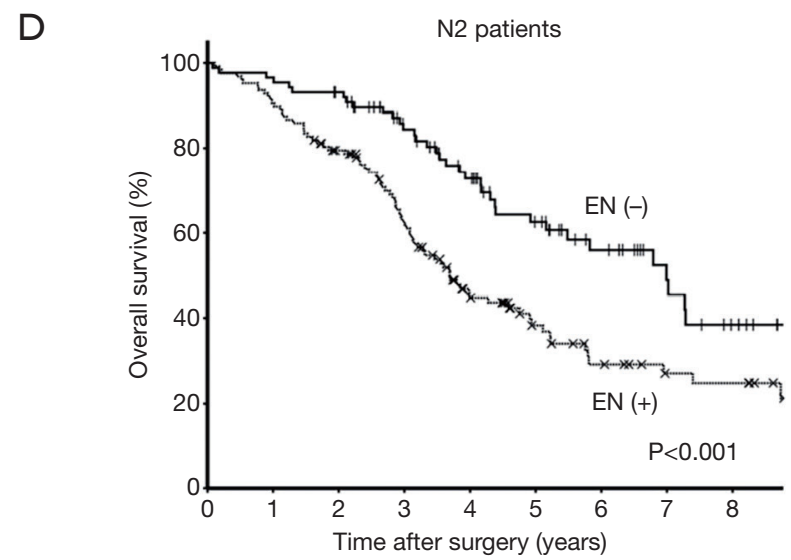

Number at risk

$\begin{array}{llllllllll}\text { EN (-) } & 88 & 85 & 80 & 62 & 48 & 35 & 23 & 14 & 8\end{array}$

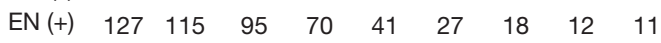

Figure 4 Overall survival curves of N1 patients stratified according to the MLNS (A) and presence of EN (B), and N2 patients according to the MLNS (C) and presence of EN (D). MLNS, size of metastatic lymph nodes; EN, extranodal extension.

in this study, we measured the diameter of true on a microscope after LN sectioning. We found that in patients with $\mathrm{N} 1$ and $\mathrm{N} 2$ stage disease, patients with MLNS $>7 \mathrm{~mm}$ showed a much worse prognosis than those with MLNS $\leq 7 \mathrm{~mm}$. We believe that this result may be attributable to the greater tumor burden and/or disease severity in those with MLNS $>7 \mathrm{~mm}$. Even without dichotomization, when MLNS was analyzed as a continuous variable, MLNS was a meaningful prognostic factor $(\mathrm{P}<0.001)$.

Lee and colleagues (18) reported that NSCLC patients with EN had a poor prognosis, regardless of the degree of LN involvement. In addition, other studies have also shown an association of $\mathrm{EN}$ with increased risk of all-cause mortality and disease recurrence $(22,23)$. Similarly, this study showed that cases with EN showed a much worse prognosis than those without EN for patients with N1 and $\mathrm{N} 2$ stage disease. We believe that the presence of $\mathrm{EN}$ indicates a severe degree of regional $\mathrm{LN}$ involvement, with simultaneous vascular and lymphatic invasion. This suggests that EN can indicate tumor severity. Therefore, systemic LN dissection should be carried out by excising all potential structures that may contain tumor, including LNs and surrounding adipose tissue within the anatomic landmarks.

To date, the efficacy of adjuvant chemotherapy for stage II or III NSCLC has been well proven (24). Based on the current guidelines, the adjuvant chemotherapy is 
recommended in $\mathrm{N} 1$ or $\mathrm{N} 2$ disease, regardless of the status of LN metastasis, MLNS or EN. Since a considerable number of candidates for adjuvant therapies choose to drop out from the recommended treatments, the clinicians might be encouraged to recommend adjuvant therapy more strongly for node-positive patients with large MLNS or EN according to our study. At our institution, only $68.5 \%$ of patients with a good general postoperative performance status received adjuvant chemotherapy following complete resection. To improve survival and achieve better outcomes, patients with risk factors outlined in this study - presence of EN or MLNS $>7 \mathrm{~mm}$ - should be monitored and observed more cautiously while pursuing more aggressive adjuvant treatments during the follow-up period.

While most operated lung cancer patients can be followed-up every 6 to 12 months postoperatively according to the surveillance guidelines $(25,26)$, it might be reasonable to adopt a more frequent follow-up strategy (27), i.e., every 3 months for the first 2 years and biannually thereafter, for patients with the presence of EN or MLNS $>7 \mathrm{~mm}$. The status of $\mathrm{LN}$ metastasis might be considered in the LN staging system for more accurate prediction of patient prognosis in the future.

Some of the limitations of our study are as follows. First, because this study is a single institutional retrospective study, confounding factors may have influenced the result. However, we tried to reduce the bias through additional subgroup analysis based on N1 and N2 disease. Second, there was no cross-validation with other independent patient groups, though our analysis was supported by statistical techniques, such as the maximal chi-square method.

\section{Conclusions}

In conclusion, MLNS and presence of EN could provide an important prognostic implication for patients with nodepositive lung ADC. To improve the prognostic predictions and treatment decisions based on the LN staging system, an evaluation of the pathologic role of MLNS and EN in patients with node-positive lung ADC may be important.

\section{Acknowledgments}

Funding: None.

\section{Footnote}

Reporting Checklist: The authors have completed the
STROBE reporting checklist. Available at http://dx.doi. org/10.21037/jtd-20-2039

Data Sharing Statement: Available at http://dx.doi. org/10.21037/jtd-20-2039

Conflicts of Interest: All authors have completed the ICMJE uniform disclosure form (available at http://dx.doi. org/10.21037/jtd-20-2039). HCY serves as an unpaid editorial board member of Fournal of Thoracic Disease from Feb 2019 to Jan 2021. The other authors have no conflicts of interest to declare.

Ethical Statement: The authors are accountable for all aspects of the work in ensuring that questions related to the accuracy or integrity of any part of the work are appropriately investigated and resolved. This study was approved by the Institutional Review of Board at the National Cancer Center (protocol number: NCC 20190064), and the requirement for patient consent was waived due to the retrospective nature of this study. The study was conducted in accordance with the Declaration of Helsinki (as revised in 2013).

Open Access Statement: This is an Open Access article distributed in accordance with the Creative Commons Attribution-NonCommercial-NoDerivs 4.0 International License (CC BY-NC-ND 4.0), which permits the noncommercial replication and distribution of the article with the strict proviso that no changes or edits are made and the original work is properly cited (including links to both the formal publication through the relevant DOI and the license). See: https://creativecommons.org/licenses/by-nc-nd/4.0/.

\section{References}

1. Rami-Porta R, Bolejack V, Crowley J, et al. The IASLC lung cancer staging project: proposals for the revisions of the $\mathrm{T}$ descriptors in the forthcoming eighth edition of the TNM classification for Lung Cancer. J Thorac Oncol 2015;10:990-1003.

2. Eberhardt WE, Mitchell A, Crowley J, et al. The IASLC lung cancer staging project: proposals for the revision of the $M$ descriptors in the forthcoming eighth edition of the TNM classification of lung cancer. J Thorac Oncol 2015;10:1515-22.

3. Goldstraw P, Chansky K, Crowley J, et al. The IASLC lung cancer staging project: proposals for revision of the 
TNM stage groupings in the forthcoming (eighth) edition of the TNM classification for lung cancer. J Thorac Oncol 2016;11:39-51.

4. Asamura H, Chansky K, Crowley J, et al. The International Association for the Study of Lung Cancer lung cancer staging project: proposals for the revision of the $\mathrm{N}$ descriptors in the forthcoming 8th edition of the TNM classification for lung cancer. J Thorac Oncol 2015;10:1675-84.

5. Luchini C, Fleischmann A, Boormans JL, et al. Extranodal extension of lymph node metastasis influences recurrence in prostate cancer: a systematic review and meta-analysis. Sci Rep 2017;7:2374.

6. Nottegar A, Veronese N, Senthil M, et al. Extra-nodal extension of sentinel lymph node metastasis is a marker of poor prognosis in breast cancer patients: A systematic review and an exploratory meta-analysis. Eur J Surg Oncol 2016;42:919-25.

7. Wu MH, Shen WT, Gosnell J, et al. Prognostic significance of extranodal extension of regional lymph node metastasis in papillary thyroid cancer. Head Neck 2015;37:1336-43.

8. Park CH, Song CM, Ji YB, et al. Significance of the extracapsular spread of metastatic lymph nodes in papillary thyroid carcinoma. Clin Exp Otorhinolaryngol 2015;8:289-94.

9. Choi AH, Blount $\mathrm{S}$, Perez MN, et al. Size of extranodal extension on sentinel lymph node dissection in the American College of Surgeons Oncology Group Z0011 Trial Era. JAMA Surg 2015;150:1141-8.

10. Märkl B, Rossle J, Arnholdt HM, et al. The clinical significance of lymph node size in colon cancer. Mod Pathol 2012;25:1413-22.

11. Altinyollar H, Berberoglu U, Gulben K, et al. The correlation of extranodal invasion with other prognostic parameters in lymph node positive breast cancer. J Surg Oncol 2007;95:567-71.

12. Miller R, Siegmund D. Maximally selected chi square statistics. Biometrics 1982;38:1011-6.

13. Halpern J. Maximally selected chi square statistics for small samples. Biometrics 1982;38:1017-23.

14. Chansky K, Detterbeck FC, Nicholson AG, et al. The IASLC lung cancer staging project: external validation of the revision of the TNM stage groupings in the eighth edition of the TNM classification of lung cancer. J Thorac Oncol 2017;12:1109-21.

15. Detterbeck FC, Chansky K, Groome P, et al. The IASLC lung cancer staging project: methodology and validation used in the development of proposals for revision of the stage classification of NSCLC in the forthcoming (eighth) edition of the TNM classification of lung cancer. J Thorac Oncol 2016;11:1433-46.

16. Luchini C, Nottegar A, Pea A, et al. Extranodal extension is an important prognostic parameter for both colonic and rectal cancer. Ann Oncol 2016;27:955-6.

17. Graafland NM, van Boven $\mathrm{HH}$, van Werkhoven E, et al. Prognostic significance of extranodal extension in patients with pathological node positive penile carcinoma. J Urol 2010;184:1347-53.

18. Lee YC, Wu CT, Kuo SW, et al. Significance of extranodal extension of regional lymph nodes in surgically resected non-small cell lung cancer. Chest 2007;131:993-9.

19. Prenzel KL, Monig SP, Sinning JM, et al. Lymph node size and metastatic infiltration in non-small cell lung cancer. Chest 2003;123:463-7.

20. Gould MK, Kuschner WG, Rydzak CE, et al. Test performance of positron emission tomography and computed tomography for mediastinal staging in patients with non-small-cell lung cancer: a meta-analysis. Ann Intern Med 2003;139:879-92.

21. Fritscher-Ravens A, Bohuslavizki KH, Brandt L, et al. Mediastinal lymph node involvement in potentially resectable lung cancer: comparison of CT, positron emission tomography, and endoscopic ultrasonography with and without fine-needle aspiration. Chest 2003;123:442-51.

22. Luchini C, Veronese N, Nottegar A, et al. Extranodal extension of nodal metastases is a poor prognostic moderator in non-small cell lung cancer: a meta-analysis. Virchows Arch 2018;472:939-47.

23. Bell AM, DeYoung BR, Weydert J. Extranodal extension in metastatic non-small cell lung cancer. Chest 2007;132:2058-9; author reply 2059-60.

24. NSCLC Meta-analyses Collaborative Group, Arriagada R, Auperin A, et al. Adjuvant chemotherapy, with or without postoperative radiotherapy, in operable non-small-cell lung cancer: two meta-analyses of individual patient data. Lancet 2010;375:1267-77.

25. Colt HG, Murgu SD, Korst RJ, et al. Follow-up and surveillance of the patient with lung cancer after curativeintent therapy: Diagnosis and management of lung cancer, 3rd ed: American College of Chest Physicians evidencebased clinical practice guidelines. Chest 2013;143:e437Se454S.

26. Postmus PE, Kerr KM, Oudkerk M, et al. Early and locally advanced non-small-cell lung cancer (NSCLC): ESMO 
Clinical Practice Guidelines for diagnosis, treatment and follow-up. Ann Oncol 2017;28:iv1-iv21.

27. Saunders M, Sculier JP, Ball D, et al. Consensus: the

Cite this article as: Moon DH, Choi JH, Yang HC, Kim MS, Lee JM, Lee GK, Jeon JH. Size and extranodal extension of metastatic lymph nodes in lung adenocarcinoma. J Thorac Dis 2020;12(11):6514-6522. doi: 10.21037/jtd-20-2039 follow-up of the treated patient. Lung Cancer 2003;42 Suppl 1:S17-9. 